\title{
Surgical wound infection in the Third World: the African experience
}

There is anecdotal, yet well-observed evidence that in many hospitals in Africa wound infection rates are high and in some hospitals almost every wound will become infected. Actual figures are hard to come by. The highest rates published reach $25 \%$ [1].

Explanations and excuses abound. The commonest reason advanced is poverty: shortage of facilities, equipment, dressings and drugs, notably antibiotics. Another group of apologists blame overcrowding, the lack of environmental hygiene and the ubiquitous presence of flies. Others say that the nutritional status of the population renders it vulnerable to infection. Some accuse the patients themselves and hold that they pick on their wounds, that they do not take their drugs and that they are dirty.

Although poverty is associated with filth, Africans, however poor and despite the scarcity of water, are remarkably clean. There is no evidence of widespread vulnerability to infection and while it is true that severely undernourished people are immunocompromised, people who have no access to food have no access to surgeons either. Environmental hygiene in many African hospitals is wanting - some should be closed because of the stench alone - still it is very unlikely that flies contribute to wound infection. The lack of facilities and utilities is regrettable, but not a sufficient reason for sepsis. The exception is water. If one has no water one should not do surgery.

The most common wounds in contemporary Africa are not 'surgical', they are accidental or wilfully inflicted lacerations. In whichever part of the body, and however old the laceration is, the wound will be washed with a 'strong' disinfectant (advertised all over Africa as the harbingers of a better, germ-free future). A surgeon-doctor-trainee-clinical assistant-nurse will scrub (possibly wearing a mask) and will put on a pair of sterile gloves, possibly recycled ones. A local anaesthetic will be given. Bleeding vessels will, perhaps, be caught and ligated. The wound will be sutured, probably with a thick silk suture. A dressing, consisting of pads and adhesives, will be applied. Tetanus toxoid will be given. A prescription will be written for an analgesic and a 5-7-day course of an oral antibiotic. No further instructions are likely to be forthcoming. Most wounds treated in this manner will become infected. Treatment of the infected wound will consist of daily application of a noxious substance of some kind, dressings and a series of different antibiotics.

If a dog had a laceration on its leg, what would it do? It would lick it, it would not walk on that leg and it would elevate that leg — provided, of course, that it could avoid being dragged to a veterinary surgeon! Most of the wounds treated thus would heal. Why not learn from the dog and clean and debride lacerations, then rest and elevate the wounded area? Most wounds treated in this manner will not hurt and will heal. Leaving a laceration unsutured in the first place is hardly ever harmful, primary suturing often is. A few might benefit from secondary suturing, either to save time, or, rarely, to improve the scar.

The commonest major operations in Africa are laparotomies. Injuries, perforations, obstructions and strangulations of viscera are frequent. Most hospitals can deal with the primary objectives of such operations: to stop bleeding; to remove the pathology and the pus; to suture holes in the viscera; and to establish continuity of gut (even if it would be better not to do so). However, lavage, if done at all, will be inadequate, for saline is scarce, sterile water in large quantities is difficult to secure and most surgeons would rather leave faeces in the abdomen than use tap water. A drain will be put in, all layers of the abdominal wall will be closed, a dressing will be applied, and an antibiotic will be prescribed. Most of these wounds will become infected and many patients will have intraperitoneal and systemic complications. An inordinate number will die.

The risk of infection can be minimised by: washing the soiled peritoneal cavity until it is clean (it is more important that the water is plentiful and warm than that it is sterile); avoiding primary anastomoses in the presence of faecal peritonitis; recognising that drains are rarely useful; leaving the skin open; washing the open wound. In addition, clinicians should not hesitate to reopen the abdomen. Antibiotics, whether for prophylaxis or therapy, must be chosen well and administered with consideration of time, route and dose.

The explanation for the high wound infection rate lies 
in the fact that the health care establishment believes that postoperative wound infection is caused exclusively by bacteria. Because of this belief the meagre resources are principally spent on trying to keep bacteria out of wounds, trying to kill bacteria in wounds with disinfectants and antibiotics and trying to protect wounds with dressings. In other words the strategy is mainly directed against contamination by exogenous bacteria and is based on barriers, chemicals and, specifically, drugs.

Postoperative wound infection is primarily caused, not by bacteria, but by surgeons. Moreover, in Africa, as elsewhere, most of the bacteria implicated are endogenous in origin. Poor surgical technique and inappropriate materials - thick silk and catgut sutures in the main - are the principal reasons for the high postoperative infection rate. Subsidiary reasons are of several kinds: severe wound contamination caused by the lack of theatre discipline (in spite of the rituals); the enthusiastic (mis)use of disinfectants; inadequate or non-existent lavage; a predilection for drains; unshakable trust in dressings; the reluctance to leave soiled wounds open; and the universal hope that, ultimately, antibiotics will eliminate and cure infections.

Bacteria are everywhere and they will find their way into the tissues, from the skin, if not the gut of the patient, from the floor, from someone's mouth, from someone's hand. The bacteria in African wounds are not more dangerous than elsewhere, perhaps less so. They are the traditional species: staphylococci, streptococci and various gram-negative bacilli. In most cases they are not yet multiresistant. The amount of contamination may be sizeable because of breaches of sterile procedure and discipline, but this is unlikely to account for the prevalence of infection. The explanation lies in the amount of devitalised tissue in the wound: tissue that was dead before or was killed during the operation. Dead cells! Cells killed by knives and scissors that do not cut, cells killed by drying, burning, heating, cooling, squashing, pressing, strangulating. Dead cells (including blood) left in the wound and cells dying after the wound has been closed, provide the culture medium in which the contaminating bacteria can thrive. And thrive they will, no matter how much antibiotic has been administered!

Probably, no operating theatre in Africa lacks a changing room; theatre attire is worn, as are masks and hats. There are sterilisers, although their efficacy is seldom tested. Much time is spent on scrubbing and gowning. Gloves are worn, but are often recycled and defective. Skin disinfection and draping is a great ceremony. Hospitals with high infection rates may well be dirty hospitals, but they are primarily hospitals with poor operating techniques and hospitals that rely on rituals rather than evidence and self examination. To understand why this is so, one needs to have a grasp of the social history and demography of surgery in Africa.

A couple of thousand surgeons work between the Sahara and the Limpopo. At least half of them are highly trained subspecialists. Presently, most surgeons operate in private hospitals and many have withdrawn altogether from teaching. High quality surgery in this part of Africa has almost entirely moved into the private sector. The standards of private hospitals vary; some are centres of excellence, yet, unforgivably, these are not teaching nor training institutions. It can be said that the best surgery and the best surgeons in tropical Africa are rarely in teaching hospitals.

The teaching hospitals are decaying. In these institutions most operations are performed by unsupervised trainees who, nowadays, are largely self-taught. In the peripheral hospitals there are no surgeons at all; doctors, with or without some surgical training, or clinical and medical assistants and nurses do the operating. These health professionals do admirably well and they save many lives, but they have not been taught careful operative techniques. It was thought that this was unnecessary because their future in the operating theatres would be short-lived: they were to be replaced by properly trained surgeons and only they would be allowed to operate, as in the West. Alas, this did not happen; the population doubled and trebled, the money ran out, the cold war ended and capitalism won. Corruption persists and the rich new upper class and the striving middle class fully engage the attentions of most of the well-trained surgeons. The poor have no access to such expertise and are operated on by people whose training was neglected or who were prevented from learning how to operate properly. At the same time most African hospitals, particularly schools of nursing, adhere to concepts of wound care that have been proved to be wrong.

The problem of wound sepsis in Africa is not a problem of science, is not due to some particular bacteria and is not a mystery. The problem is the almost universal belief in harmful practices, the lack of updated teaching, hollow routines and thoughtless rituals. The problem is further compounded by the medical and the pharmaceutical industry who benefit from the prevailing situation in order to peddle drugs and material purported to be beneficial to wound healing.

The high wound infection rates in Africa and the attendant high morbidity and mortality are ultimately the result of two modern misconceptions and of the adherence to two ancient beliefs. The dual misconceptions that wound infection is primarily caused by bacteria, and that no-one but a fully trained surgeon can understand the principles of surgery originated from within the surgical profession. That wounds must 
be closed and sealed and that some substances enhance healing are ancient beliefs encouraged by the sellers of all manner of merchandise for thousands of years. Amazingly, people continue putting substances into wounds that they would never put into their eyes!

Bacteriologists would do well to teach, firstly, that surgeons must strive to minimise contamination of wounds, but that some degree of contamination is unavoidable. Secondly, that living tissue can cope with astonishingly massive bacterial loads, but, as dead cells are a fine culture medium, the single most important measure in the prevention of wound infection is to treat every cell of the patient with care and respect. Lastly, that there is one substance, the copious use of which before, during and after surgery will dramatically diminish wound infection rates. That substance is water.

IMRE J. P. LOEFLER

Nairobi Hospital, Argwings-Kodhek Road, PO Box 47964, Nairobi, Kenya

\section{Reference}

1. Sani PG, Kodwavwala MYD. Wound infections at the Kenyatta National Hospital. Proc Assoc Surg East Afr 1991; 14: 36-38. 